Acta Crystallographica Section E

Structure Reports

Online

ISSN 1600-5368

\section{2-Hydroxy-3-methoxybenzaldehyde (o-vanillin) revisited}

\section{David Shin $^{\mathrm{a}}$ and Peter Müller ${ }^{\mathrm{b} *}$}

aPhillips Academy, 180 Main St, Andover, MA 01810, USA, and ${ }^{\mathbf{b} X-R a y ~ D i f f r a c t i o n}$ Facility, MIT Department of Chemistry, 77 Massachusetts Avenue, Building 2, Room 325, Cambridge, MA 02139-4307, USA

Correspondence e-mail: pmueller@mit.edu

Received 12 June 2012; accepted 28 June 2012

Key indicators: single-crystal X-ray study; $T=100 \mathrm{~K}$; mean $\sigma(\mathrm{C}-\mathrm{C})=0.002 \AA$; $R$ factor $=0.034 ; w R$ factor $=0.095 ;$ data-to-parameter ratio $=11.6$.

The structure of ortho-vanillin, $\mathrm{C}_{8} \mathrm{H}_{8} \mathrm{O}_{3}$, has been revisited with modern methods and at low temperature $(100 \mathrm{~K})$. The previous structure [Iwasaki et al. (1976). Acta Cryst. B32, 1264-1266] is confirmed, but geometric precision is improved by an order of magnitude. The $\mathrm{C}$ atom of the methoxy group lies close to the benzene ring plane, which is the most common geometry for -OMe groups lying ortho to $-\mathrm{OH}$ groups on an aromatic ring. The crystal structure displays one intramolecular $\mathrm{O}-\mathrm{H} \cdots \mathrm{O}$ and three weak intermolecular $\mathrm{C}-$ $\mathrm{H}$.. O hydrogen bonds.

\section{Related literature}

For the original structure of $o$-vanillin, see: Iwasaki et al. (1976). For C-H . acceptor interactions, see: Steiner (1996). For a summary of general refinement techniques applied, see: Müller (2009). For a description of the Cambridge Structural Database, see: Allen (2002).

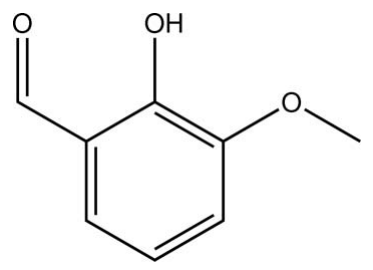

\section{Experimental}

Crystal data

$\mathrm{C}_{8} \mathrm{H}_{8} \mathrm{O}_{3}$

$M_{r}=152.14$

Orthorhombic, Fdd2

$a=24.367$ (5) ̊

$b=24.407$ (3) $\AA$

$c=4.7786(5) \AA$

\section{Data collection \\ Bruker SMART APEXII CCD diffractometer \\ Absorption correction: multi-scan (SADABS; Sheldrick, 2009) \\ $T_{\min }=0.709, T_{\max }=1.000$}

Refinement

$R\left[F^{2}>2 \sigma\left(F^{2}\right)\right]=0.034$

$w R\left(F^{2}\right)=0.095$

$S=1.11$

1203 reflections

104 parameters

2 restraints

Table 1

Selected torsion angles $\left(^{\circ}\right)$.

\begin{tabular}{llll}
\hline $\mathrm{C} 8-\mathrm{O} 3-\mathrm{C} 3-\mathrm{C} 4$ & $7.5(2)$ & $\mathrm{C} 8-\mathrm{O} 3-\mathrm{C} 3-\mathrm{C} 2$ & $-172.98(13)$ \\
\hline
\end{tabular}

Table 2

Hydrogen-bond geometry $\left(\AA{ }^{\circ}\right)$.

\begin{tabular}{lllll}
\hline$D-\mathrm{H} \cdots A$ & $D-\mathrm{H}$ & $\mathrm{H} \cdots A$ & $D \cdots A$ & $D-\mathrm{H} \cdots A$ \\
\hline $\mathrm{O} 2-\mathrm{H} 2 \cdots \mathrm{O} 1$ & $0.85(2)$ & $1.84(2)$ & $2.6017(17)$ & $148(2)$ \\
$\mathrm{C} 8-\mathrm{H} 8 B \cdots \mathrm{O} 1^{\mathrm{i}}$ & 0.98 & 2.56 & $3.064(2)$ & 112 \\
$\mathrm{C} 6-\mathrm{H} 6 \cdots \mathrm{O}^{\text {ii }}$ & 0.95 & 2.53 & $3.374(2)$ & 149 \\
$\mathrm{C} 7-\mathrm{H} 7 \cdots 3^{\text {ii }}$ & 0.95 & 2.59 & $3.414(2)$ & 146 \\
\hline
\end{tabular}

Symmetry codes: (i) $-x+\frac{3}{4}, y+\frac{1}{4}, z-\frac{5}{4}$; (ii) $x+\frac{1}{4},-y+\frac{1}{4}, z+\frac{1}{4}$.

Table 3

Comparison $(\AA)$ between the room and low temperature structures of $o$ vanillin.

\begin{tabular}{lll}
\hline parameter & room tempreature & low temperature (this study) \\
\hline$R 1[I>2 \sigma(I)]$ & 0.077 & 0.034 \\
$\mathrm{C} 1-\mathrm{C} 7$ & 1.427 & $1.452(2)$ \\
$\mathrm{O} 1-\mathrm{C} 7$ & 1.229 & $1.233(2)$ \\
$\mathrm{O} 2-\mathrm{C} 2$ & 1.354 & $1.3535(17)$ \\
$\mathrm{O} 3-\mathrm{C} 3$ & 1.364 & $1.3689(16)$ \\
$\mathrm{O} 3-\mathrm{C} 8$ & 1.430 & $1.434(2)$ \\
\hline
\end{tabular}

Data collection: APEX2 (Bruker, 2011); cell refinement: SAINT (Bruker, 2011); data reduction: $S A I N T$; $\operatorname{program}(\mathrm{s})$ used to solve structure: SHELXS97 (Sheldrick, 2008); program(s) used to refine structure: SHELXL97 (Sheldrick, 2008); molecular graphics: SHELXTL (Sheldrick, 2008); software used to prepare material for publication: SHELXTLand PLATON (Spek, 2009).

The diffractometer was purchased with the help of funding from the National Science Foundation (NSF) under grant No. CHE-0946721. DS and PM would like to thank Jeff Simpson for kindly providing the $o$-vanillin crystals.

Supplementary data and figures for this paper are available from the IUCr electronic archives (Reference: HB6851). 


\section{organic compounds}

\section{References}

Allen, F. H. (2002). Acta Cryst. B58, 380-388.

Bruker (2011). APEX2 and SAINT. Bruker AXS Inc., Madison, Wisconsin, USA.

Iwasaki, F., Tanaka, I. \& Aihara, A. (1976). Acta Cryst. B32, 1264-1266.
Müller, P. (2009). Crystallogr. Rev. 15, 57-83.

Sheldrick, G. M. (2008). Acta Cryst. A64, 112-122.

Sheldrick, G. M. (2009). SADABS. University of Göttingen, Germany.

Spek, A. L. (2009). Acta Cryst. D65, 148-155.

Steiner, Th. (1996). Crystallogr. Rev. 6, 1-57. 


\section{supporting information}

Acta Cryst. (2012). E68, o2336-o2337 [https://doi.org/10.1107/S1600536812029571]

\section{2-Hydroxy-3-methoxybenzaldehyde (o-vanillin) revisited}

\section{David Shin and Peter Müller}

\section{S1. Comment}

The only published crystal structure of $o$-vanillin was determined almost 40 years ago at room temperature and based on Weissenberg films (Iwasaki et al. 1976). This structure has been redetermined to current standards with modern methods and state-of-the-art equipment. No discrepancies were found between the two structures, however the residual values of the refinement as well as standard uncertainties on bond lengths and angles are significantly improved in the modern structure. Iwasaki et al. (1976) report standard uncertainties for bonds between non-hydrogen atoms of $0.011 \AA$ to 0.03 $\AA$, while standard uncertainties in this study range from $0.0016 \AA$ to $0.002 \AA$. The residual value of the refinement for "observed reflexions" in the structure by Iwasaki et al. (1976) is reported as 0.077 , while the low-temperature structure could be refined to an $R 1$ of 0.034 for $I>2 \sigma(I)$ (see also Table 3 ).

The atomic labeling scheme for non-hydrogen atoms was chosen to match that of Iwasaki et al. (1976) and a direct comparison between the structures reveals that most bond distances were found to be somewhat shorter in the room temperature structure than at low temperature (see Table 3). This is probably a result of libration effects, which are more pronounced at higher temperatures. Iwasaki et al. (1976) report the bond between C5 and C6 to be significantly shorter than all other bonds in the benzene ring and point out that this was a phenomenon observed in other related structures (namely iso-vanillin and 2,6-dinitrophenol). Indeed, the bond between C5 and C6 is the shortest of the six aromatic bonds, however in the low-temperature structure there are four long and two short aromatic $\mathrm{C}-\mathrm{C}$ bonds. The long bonds range from 1.403 (2) to 1.409 (2) $\AA$, the short ones are 1.385 (2) $\AA$ (C3-C4) and 1.379 (2) $\AA$ (C5-C6).

The benzene ring of $o$-vanillin is almost planar in the solid state, with a root-mean-square deviation of $0.0054 \AA$. The methoxy group is rotated out of this plane by about $7^{\circ}$ (see Table 1). This is a common torsion angle for methoxy groups standing ortho to hydroxyl functions. A search of the Cambridge Structure Data Base (Allen, 2002) for this geometric feature (only error free, organic structures with $R$-values below $10 \%$ were considered) resulted in 1230 hits (from 825 structures) and the torsion angles in question cluster around two different values: $0^{\circ}$ and $\pm 30^{\circ}$. Figure 3 shows a scatterplot of all results from this search. 915 of the 1230 hits (74.4\%) fall between $-10^{\circ}$ and $+10^{\circ}$, with an average torsion angle of $-0.163^{\circ}$ while $276\left(22.4 \%\right.$ ) belong to the $\pm 30^{\circ}$ torsion angle group (average values calculated separately for the ranges $-25^{\circ}$ to $-35^{\circ}$ and $25^{\circ}$ to $35^{\circ}$ are $-31.586^{\circ}$ and $31.397^{\circ}$, respectively), and 39 hits ( $3.2 \%$ of all hits) fall outside the specified ranges.

In addition to the obvious intramolecular hydrogen bond between $\mathrm{O} 1$ and $\mathrm{O} 2$ that was already described by Iwasaki $e t$ al. (1976), the program PLATON (Spek, 2009) finds three weak C- $\mathrm{H} \cdots \mathrm{O}$ interactions (Steiner, 1996, Table 2). One of them, $\mathrm{C} 8-\mathrm{H} 8 \mathrm{~B} \cdots \mathrm{O} 1^{\mathrm{i}}$, connects the $o$-vanillin molecules into almost flat, indefinite zigzag chains extending parallel to the $b$-c plane. The other two, $\mathrm{C} 6-\mathrm{H} 6 \cdots \mathrm{O}^{\mathrm{ii}}$ and $\mathrm{C} 7-\mathrm{H} 7 \cdots \mathrm{O} 3^{\mathrm{ii}}$, crosslink those chains, giving rise to the supramolecular network shown in Figure 2 (symmetry codes: i: $3 / 4-x, 1 / 4+y,-5 / 4+z$; ii: $1 / 4+x, 1 / 4-y, 1 / 4+z$ ). 


\section{S2. Experimental}

Ortho-vanillin was obtained from Fluka in the form of yellow plates and used without recrystallization.

\section{S3. Refinement}

The structure was refined against $F^{2}$ on all data by full-matrix least squares with SHELXL97 (Sheldrick, 2008), following established refinement strategies (Müller, 2009). All non-hydrogen atoms were refined anisotropically. All hydrogen atoms binding to carbon were included into the model at geometrically calculated positions ( $\mathrm{C}-\mathrm{H}$ target distance $0.98 \AA$ for methyl hydrogen atoms, $0.95 \AA$ for all others) and refined using a riding model. The torsion angle of the methyl group was allowed to refine. Coordinates for the hydrogen atom on $\mathrm{O} 2$ were taken from the difference Fourier synthesis. This hydrogen atom was subsequently refined semi-freely using a distance resraint for the $\mathrm{O}-\mathrm{H}$ bond (target value 0.84 (2) $\AA)$. The $U_{\text {iso }}$ values of all hydrogen atoms were constrained to $1.2 U_{\text {eq }}$ (1.5 times for hydroxyl and methyl $\mathrm{H}$ atoms) of the respective atom to which the hydrogen atom bonds. Anomalous dispersion was negligible and Friedel pairs were merged before refinement.

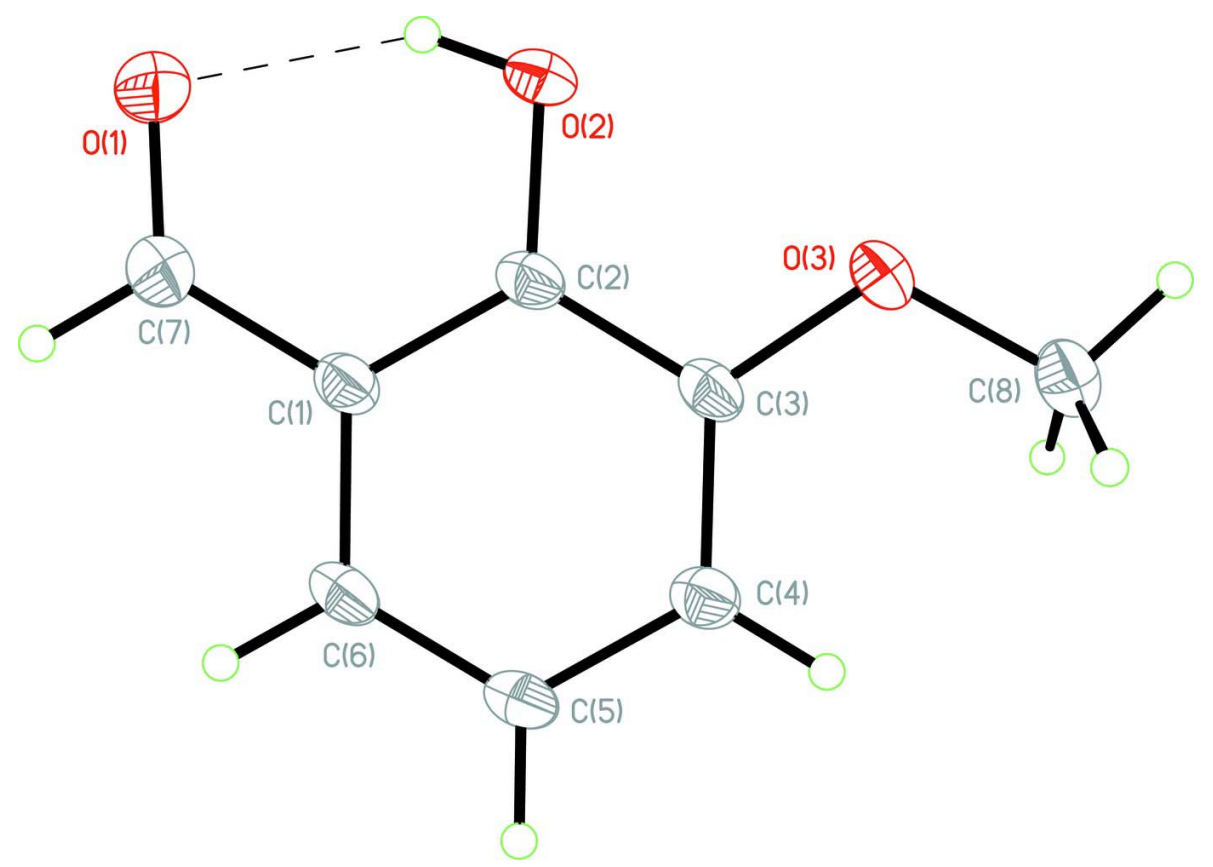

Figure 1

The molecular structure of the title compound with displacement ellipsoids shown at the $50 \%$ probability level. 


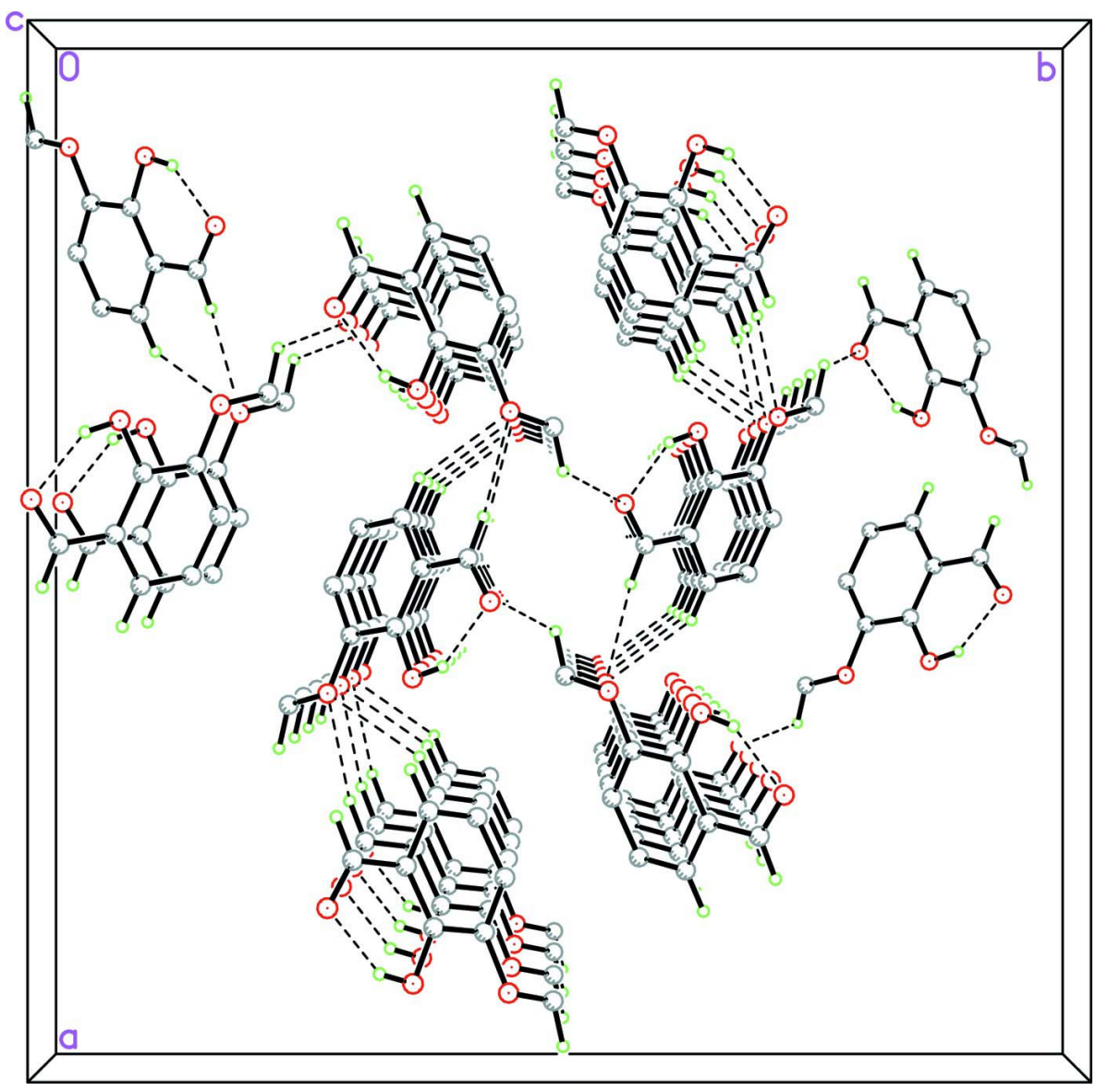

Figure 2

Packing diagram of the title compound in a projection along the $c$ axis. Hydrogen bonds are shown as dashed lines. This projection was chosen for easier comparison with Figure 3 in Iwasaki et al. (1976). 


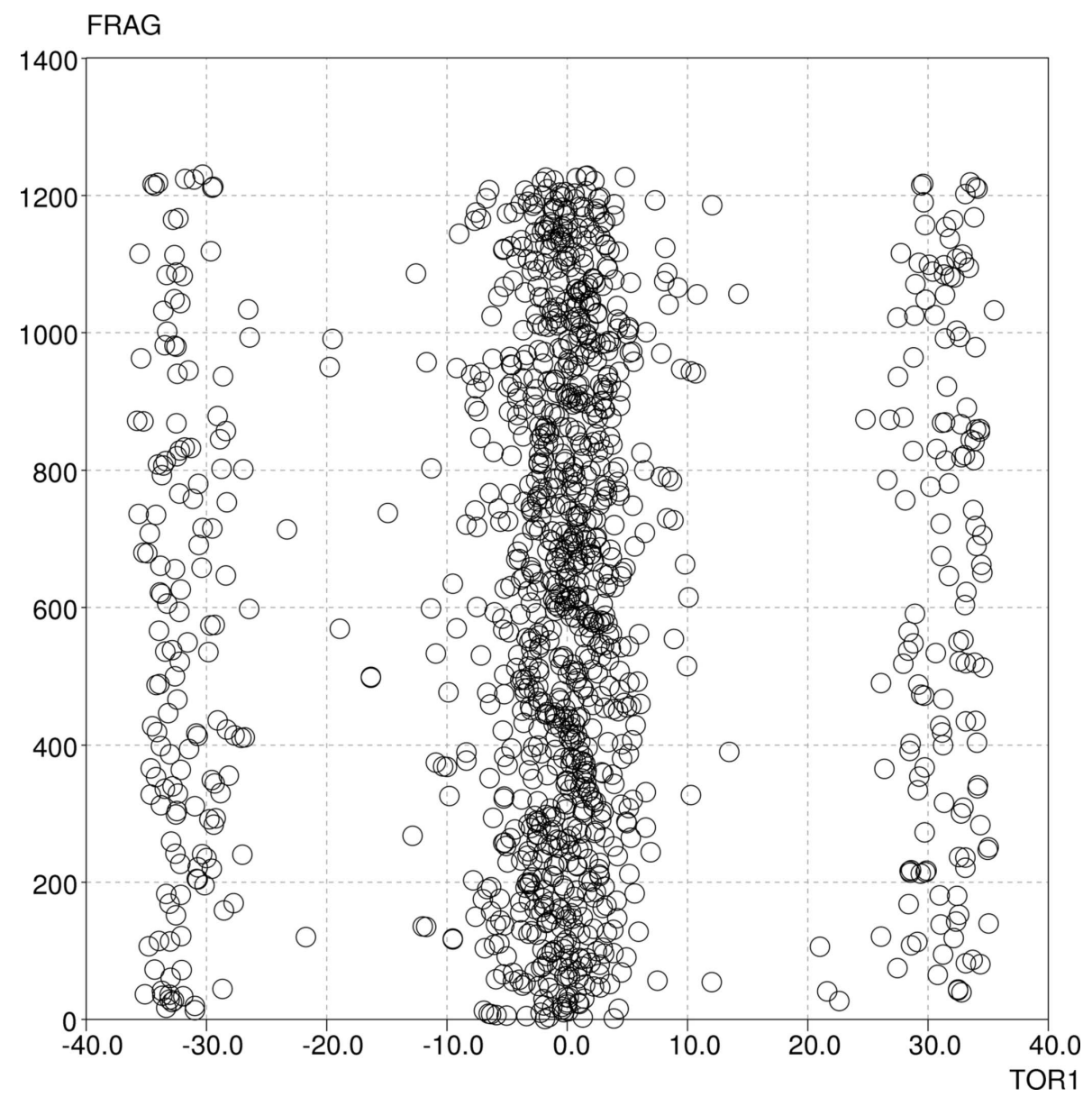

Figure 3

Scatterplot showing ranges of torsion angles on ortho substituted methoxy-hydroxy aryls. $74.4 \%$ of the torsion angles are close to zero (as in the structure of $o$-vanillin), while $22.4 \%$ are reported to be close to $\pm 30^{\circ}$.

2-Hydroxy-3-methoxybenzaldehyde

\section{Crystal data}

$\mathrm{C}_{8} \mathrm{H}_{8} \mathrm{O}_{3}$

$M_{r}=152.14$

Orthorhombic, $F d d 2$

$a=24.367(5) \AA$

$b=24.407$ (3) $\AA$

$c=4.7786(5) \AA$

$V=2842.0(7) \AA^{3}$

$Z=16$

$F(000)=1280$

Data collection

Bruker SMART APEXII CCD

diffractometer

Radiation source: $\mathrm{I} \mu \mathrm{S}$ micro-focus sealed tube Incoatech $\mathrm{I} \mu \mathrm{S}$ multilayer optics monochromator Detector resolution: 8.3 pixels $\mathrm{mm}^{-1}$ $\varphi$ and $\omega$ scans
$D_{\mathrm{x}}=1.422 \mathrm{Mg} \mathrm{m}^{-3}$

Mo $K \alpha$ radiation, $\lambda=0.71073 \AA$

Cell parameters from 9845 reflections

$\theta=2.4-30.5^{\circ}$

$\mu=0.11 \mathrm{~mm}^{-1}$

$T=100 \mathrm{~K}$

Plate, yellow

$0.45 \times 0.20 \times 0.06 \mathrm{~mm}$

Absorption correction: multi-scan

(SADABS; Sheldrick, 2009)

$T_{\min }=0.709, T_{\max }=1.000$

21987 measured reflections

1203 independent reflections

1153 reflections with $I>2 \sigma(I)$ 


$$
\begin{aligned}
& R_{\text {int }}=0.053 \\
& \theta_{\max }=30.5^{\circ}, \theta_{\min }=2.4^{\circ} \\
& h=-34 \rightarrow 34
\end{aligned}
$$

\section{Refinement}

\section{Refinement on $F^{2}$}

Least-squares matrix: full

$R\left[F^{2}>2 \sigma\left(F^{2}\right)\right]=0.034$

$w R\left(F^{2}\right)=0.095$

$S=1.11$

1203 reflections

104 parameters

2 restraints

Primary atom site location: structure-invariant direct methods $k=-34 \rightarrow 34$

$l=-6 \rightarrow 6$

Secondary atom site location: difference Fourier map

Hydrogen site location: inferred from neighbouring sites

$\mathrm{H}$ atoms treated by a mixture of independent and constrained refinement

$w=1 /\left[\sigma^{2}\left(F_{\mathrm{o}}^{2}\right)+(0.0544 P)^{2}+2.2598 P\right]$ where $P=\left(F_{\mathrm{o}}^{2}+2 F_{\mathrm{c}}^{2}\right) / 3$

$(\Delta / \sigma)_{\max }<0.001$

$\Delta \rho_{\max }=0.32 \mathrm{e} \AA^{-3}$

$\Delta \rho_{\min }=-0.21 \mathrm{e} \AA^{-3}$

\section{Special details}

Experimental. Low-temperature diffraction data were collected on a Bruker-AXS X8 Kappa Duo four-circle diffractometer coupled to a Smart Apex 2 CCD detector, performing $\varphi$ and $\omega$ scans, using Mo $\mathrm{K}_{\alpha}$ radiation $(\lambda=0.71073 \AA)$ from an Incoateac $\mathrm{I} \mu \mathrm{S}$ micro-source. The instrument was purchased with the help of funding from the National Science Foundation (NSF) under Grant Number CHE-0946721.

Geometry. All e.s.d.'s (except the e.s.d. in the dihedral angle between two 1.s. planes) are estimated using the full covariance matrix. The cell e.s.d.'s are taken into account individually in the estimation of e.s.d.'s in distances, angles and torsion angles; correlations between e.s.d.'s in cell parameters are only used when they are defined by crystal symmetry. An approximate (isotropic) treatment of cell e.s.d.'s is used for estimating e.s.d.'s involving 1.s. planes.

Refinement. Refinement of $F^{2}$ against ALL reflections. The weighted $R$-factor $w R$ and goodness of fit $S$ are based on $F^{2}$, conventional $R$-factors $R$ are based on $F$, with $F$ set to zero for negative $F^{2}$. The threshold expression of $F^{2}>\sigma\left(F^{2}\right)$ is used only for calculating $R$-factors (gt) etc. and is not relevant to the choice of reflections for refinement. $R$-factors based on $F^{2}$ are statistically about twice as large as those based on $F$, and $R$ - factors based on ALL data will be even larger.

Fractional atomic coordinates and isotropic or equivalent isotropic displacement parameters $\left(\AA^{2}\right)$

\begin{tabular}{lllll}
\hline & $x$ & $y$ & $z$ & $U_{\text {iso }} * / U_{\text {eq }}$ \\
\hline O1 & $0.45674(5)$ & $0.05966(5)$ & $1.0153(3)$ & $0.0291(3)$ \\
O2 & $0.38924(4)$ & $0.12815(5)$ & $0.7797(3)$ & $0.0247(2)$ \\
H2 & $0.3995(10)$ & $0.1013(8)$ & $0.880(5)$ & $0.037^{*}$ \\
O3 & $0.37296(4)$ & $0.20682(5)$ & $0.4128(3)$ & $0.0245(3)$ \\
C1 & $0.48543(6)$ & $0.12138(6)$ & $0.6601(4)$ & $0.0202(3)$ \\
C2 & $0.43287(5)$ & $0.14455(6)$ & $0.6257(3)$ & $0.0195(3)$ \\
C3 & $0.42513(5)$ & $0.18616(6)$ & $0.4251(3)$ & $0.0199(3)$ \\
C4 & $0.46886(6)$ & $0.20316(6)$ & $0.2616(3)$ & $0.0213(3)$ \\
H4 & 0.4635 & 0.2311 & 0.1258 & $0.026^{*}$ \\
C5 & $0.52111(6)$ & $0.17949(6)$ & $0.2945(4)$ & $0.0226(3)$ \\
H5 & 0.5507 & 0.1910 & 0.1795 & $0.027^{*}$ \\
C6 & $0.52928(6)$ & $0.13949(6)$ & $0.4940(3)$ & $0.0225(3)$ \\
H6 & 0.5648 & 0.1241 & 0.5191 & $0.027^{*}$ \\
C7 & $0.49383(6)$ & $0.07907(6)$ & $0.8706(4)$ & $0.0248(3)$ \\
H7 & 0.5300 & 0.0656 & 0.8980 & $0.030^{*}$ \\
C8 & $0.36098(6)$ & $0.24468(7)$ & $0.1915(4)$ & $0.0273(3)$ \\
H8A & 0.3821 & 0.2784 & 0.2194 & $0.041^{*}$ \\
H8B & 0.3217 & 0.2533 & 0.1925 & $0.041^{*}$
\end{tabular}


$\mathrm{H} 8 \mathrm{C}$

0.3709

0.2282

0.0114

$0.041^{*}$

Atomic displacement parameters $\left(\AA^{2}\right)$

\begin{tabular}{lllllll}
\hline & $U^{11}$ & $U^{22}$ & $U^{33}$ & $U^{12}$ & $U^{13}$ & $U^{23}$ \\
\hline O1 & $0.0248(5)$ & $0.0320(5)$ & $0.0306(6)$ & $-0.0029(4)$ & $0.0006(5)$ & $0.0070(5)$ \\
O2 & $0.0143(4)$ & $0.0318(5)$ & $0.0280(6)$ & $-0.0018(4)$ & $0.0044(5)$ & $0.0051(5)$ \\
O3 & $0.0145(4)$ & $0.0297(5)$ & $0.0293(6)$ & $0.0034(4)$ & $-0.0005(4)$ & $0.0041(5)$ \\
C1 & $0.0142(5)$ & $0.0247(6)$ & $0.0218(6)$ & $-0.0006(4)$ & $-0.0003(5)$ & $-0.0001(6)$ \\
C2 & $0.0135(5)$ & $0.0237(6)$ & $0.0213(6)$ & $-0.0025(4)$ & $0.0009(5)$ & $-0.0007(5)$ \\
C3 & $0.0127(5)$ & $0.0249(6)$ & $0.0222(6)$ & $0.0002(4)$ & $-0.0009(5)$ & $-0.0010(5)$ \\
C4 & $0.0173(6)$ & $0.0244(6)$ & $0.0222(7)$ & $-0.0020(5)$ & $0.0006(5)$ & $0.0001(6)$ \\
C5 & $0.0150(5)$ & $0.0281(6)$ & $0.0248(7)$ & $-0.0020(5)$ & $0.0036(6)$ & $-0.0007(6)$ \\
C6 & $0.0131(5)$ & $0.0284(6)$ & $0.0261(8)$ & $-0.0006(4)$ & $0.0004(5)$ & $-0.0013(6)$ \\
C7 & $0.0210(6)$ & $0.0273(6)$ & $0.0261(7)$ & $-0.0001(5)$ & $-0.0017(6)$ & $0.0021(6)$ \\
C8 & $0.0212(6)$ & $0.0305(7)$ & $0.0304(8)$ & $0.0058(5)$ & $-0.0016(6)$ & $0.0029(7)$ \\
& & & & & &
\end{tabular}

Geometric parameters $\left(\AA,{ }^{\circ}\right)$

\begin{tabular}{|c|c|c|c|}
\hline $\mathrm{O} 1-\mathrm{C} 7$ & $1.233(2)$ & $\mathrm{C} 4-\mathrm{C} 5$ & $1.4070(19)$ \\
\hline $\mathrm{O} 2-\mathrm{C} 2$ & $1.3535(17)$ & $\mathrm{C} 4-\mathrm{H} 4$ & 0.9500 \\
\hline $\mathrm{O} 2-\mathrm{H} 2$ & $0.850(17)$ & $\mathrm{C} 5-\mathrm{C} 6$ & $1.379(2)$ \\
\hline $\mathrm{O} 3-\mathrm{C} 3$ & $1.3689(16)$ & $\mathrm{C} 5-\mathrm{H} 5$ & 0.9500 \\
\hline $\mathrm{O} 3-\mathrm{C} 8$ & $1.434(2)$ & $\mathrm{C} 6-\mathrm{H} 6$ & 0.9500 \\
\hline $\mathrm{C} 1-\mathrm{C} 6$ & $1.403(2)$ & $\mathrm{C} 7-\mathrm{H} 7$ & 0.9500 \\
\hline $\mathrm{C} 1-\mathrm{C} 2$ & $1.4094(19)$ & $\mathrm{C} 8-\mathrm{H} 8 \mathrm{~A}$ & 0.9800 \\
\hline $\mathrm{C} 1-\mathrm{C} 7$ & $1.456(2)$ & $\mathrm{C} 8-\mathrm{H} 8 \mathrm{~B}$ & 0.9800 \\
\hline $\mathrm{C} 2-\mathrm{C} 3$ & $1.409(2)$ & $\mathrm{C} 8-\mathrm{H} 8 \mathrm{C}$ & 0.9800 \\
\hline $\mathrm{C} 3-\mathrm{C} 4$ & $1.385(2)$ & & \\
\hline $\mathrm{C} 2-\mathrm{O} 2-\mathrm{H} 2$ & $107.6(18)$ & $\mathrm{C} 6-\mathrm{C} 5-\mathrm{H} 5$ & 120.0 \\
\hline $\mathrm{C} 3-\mathrm{O} 3-\mathrm{C} 8$ & $117.24(13)$ & $\mathrm{C} 4-\mathrm{C} 5-\mathrm{H} 5$ & 120.0 \\
\hline $\mathrm{C} 6-\mathrm{C} 1-\mathrm{C} 2$ & $119.99(14)$ & $\mathrm{C} 5-\mathrm{C} 6-\mathrm{C} 1$ & $120.28(13)$ \\
\hline $\mathrm{C} 6-\mathrm{C} 1-\mathrm{C} 7$ & $120.49(13)$ & $\mathrm{C} 5-\mathrm{C} 6-\mathrm{H} 6$ & 119.9 \\
\hline $\mathrm{C} 2-\mathrm{C} 1-\mathrm{C} 7$ & $119.52(14)$ & $\mathrm{C} 1-\mathrm{C} 6-\mathrm{H} 6$ & 119.9 \\
\hline $\mathrm{O} 2-\mathrm{C} 2-\mathrm{C} 3$ & $118.53(12)$ & $\mathrm{O} 1-\mathrm{C} 7-\mathrm{C} 1$ & $123.86(14)$ \\
\hline $\mathrm{O} 2-\mathrm{C} 2-\mathrm{C} 1$ & $122.13(14)$ & $\mathrm{O} 1-\mathrm{C} 7-\mathrm{H} 7$ & 118.1 \\
\hline $\mathrm{C} 3-\mathrm{C} 2-\mathrm{C} 1$ & $119.35(13)$ & $\mathrm{C} 1-\mathrm{C} 7-\mathrm{H} 7$ & 118.1 \\
\hline $\mathrm{O} 3-\mathrm{C} 3-\mathrm{C} 4$ & $125.45(14)$ & $\mathrm{O} 3-\mathrm{C} 8-\mathrm{H} 8 \mathrm{~A}$ & 109.5 \\
\hline $\mathrm{O} 3-\mathrm{C} 3-\mathrm{C} 2$ & $114.77(12)$ & $\mathrm{O} 3-\mathrm{C} 8-\mathrm{H} 8 \mathrm{~B}$ & 109.5 \\
\hline $\mathrm{C} 4-\mathrm{C} 3-\mathrm{C} 2$ & $119.78(12)$ & $\mathrm{H} 8 \mathrm{~A}-\mathrm{C} 8-\mathrm{H} 8 \mathrm{~B}$ & 109.5 \\
\hline $\mathrm{C} 3-\mathrm{C} 4-\mathrm{C} 5$ & $120.67(14)$ & $\mathrm{O} 3-\mathrm{C} 8-\mathrm{H} 8 \mathrm{C}$ & 109.5 \\
\hline $\mathrm{C} 3-\mathrm{C} 4-\mathrm{H} 4$ & 119.7 & $\mathrm{H} 8 \mathrm{~A}-\mathrm{C} 8-\mathrm{H} 8 \mathrm{C}$ & 109.5 \\
\hline $\mathrm{C} 5-\mathrm{C} 4-\mathrm{H} 4$ & 119.7 & $\mathrm{H} 8 \mathrm{~B}-\mathrm{C} 8-\mathrm{H} 8 \mathrm{C}$ & 109.5 \\
\hline $\mathrm{C} 6-\mathrm{C} 5-\mathrm{C} 4$ & $119.92(14)$ & & \\
\hline $\mathrm{C} 2-\mathrm{C} 1-\mathrm{C} 7-\mathrm{O} 1$ & $3.8(3)$ & $\mathrm{C} 8-\mathrm{O} 3-\mathrm{C} 3-\mathrm{C} 2$ & $-172.98(13)$ \\
\hline $\mathrm{C} 8-\mathrm{O} 3-\mathrm{C} 3-\mathrm{C} 4$ & $7.5(2)$ & $\mathrm{C} 6-\mathrm{C} 1-\mathrm{C} 7-\mathrm{O} 1$ & $-176.85(16)$ \\
\hline
\end{tabular}


supporting information

Hydrogen-bond geometry $\left(\AA,{ }^{\circ}\right)$

\begin{tabular}{lllll}
\hline$D-\mathrm{H} \cdots A$ & $D-\mathrm{H}$ & $\mathrm{H} \cdots A$ & $D \cdots A$ & $D-\mathrm{H} \cdots A$ \\
\hline $\mathrm{O} 2-\mathrm{H} 2 \cdots \mathrm{O} 1$ & $0.85(2)$ & $1.84(2)$ & $2.6017(17)$ & $148(2)$ \\
$\mathrm{C} 8-\mathrm{H} 8 B \cdots \mathrm{O} 1^{\mathrm{i}}$ & 0.98 & 2.56 & $3.064(2)$ & 112 \\
$\mathrm{C} 6-\mathrm{H} 6 \cdots 3^{\mathrm{ii}}$ & 0.95 & 2.53 & $3.374(2)$ & 149 \\
$\mathrm{C} 7-\mathrm{H} 7 \cdots{ }^{\mathrm{ii}}$ & 0.95 & 2.59 & $3.414(2)$ & 146 \\
\hline
\end{tabular}

Symmetry codes: (i) $-x+3 / 4, y+1 / 4, z-5 / 4$; (ii) $x+1 / 4,-y+1 / 4, z+1 / 4$. 